
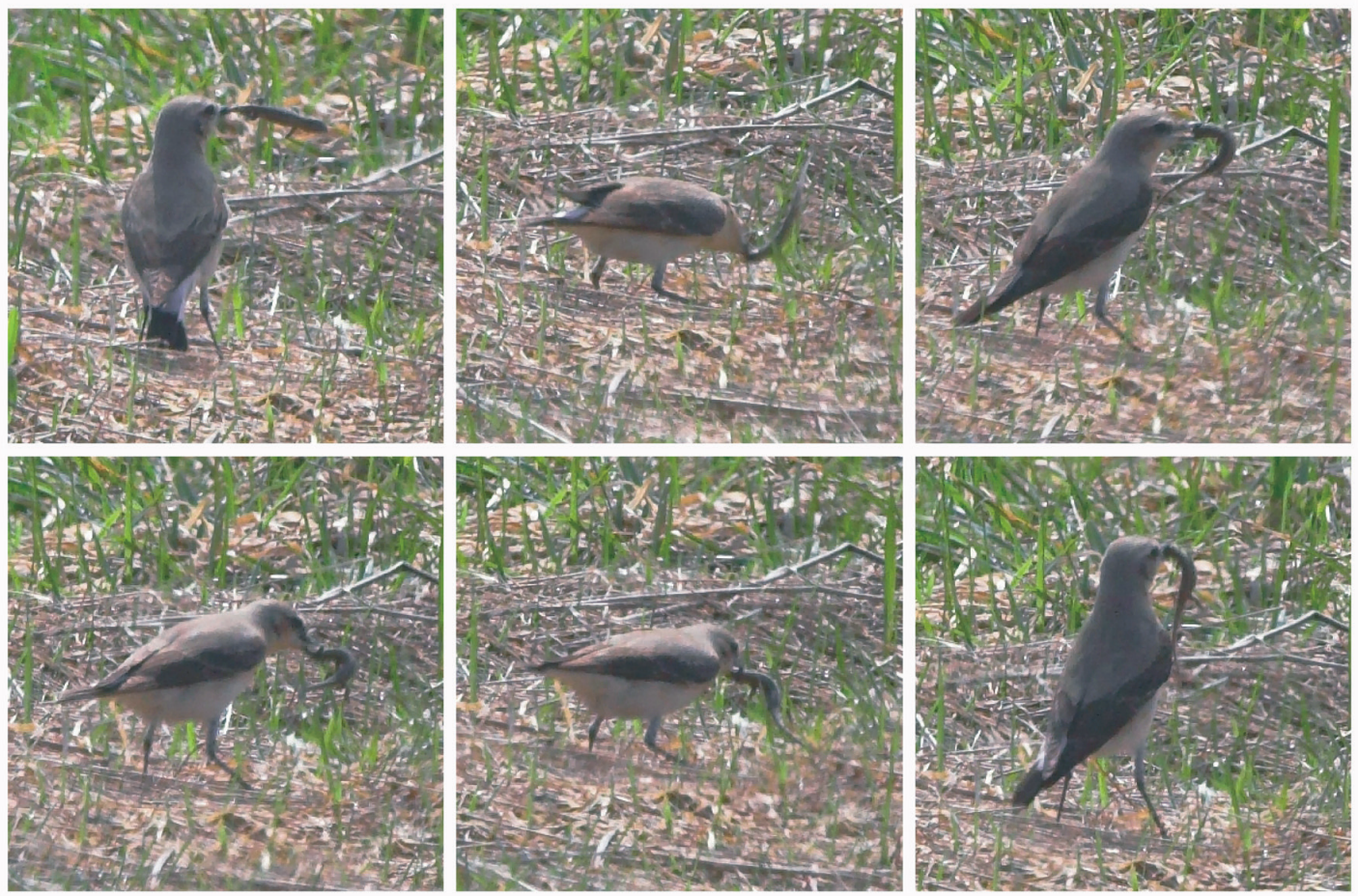

Figure 2. Handling the newt by Northern Wheatear Oenanthe oenanthe (7 April 2012, Carpathians, SE Poland). Stenskvätta hanterar salamander

https://doi.org/10.34080/os.v23.22577

\section{Rasen hornemanni av snösiska Carduelis hornemanni aldrig säkert anträffad i Sverige}

\author{
Subspecies hornemanni of Arctic \\ Redpoll Carduelis hornemanni never \\ recorded in Sweden
}

\section{LARS SVENSSON}

Snösiskan Carduelis hornemanni förekommer i två olika underarter, den mindre exilipes som häckar i nordligaste Fennoskandien och vidare österut i norra Ryssland och Sibirien, och som uppträder sällsynt men relativt regelbundet vintertid i södra och mellersta Sverige, och den mer storvuxna hornemanni som häckar på norra Grönland och i delar av arktiska Nordamerika, men som av allt att döma även häckar på norra Island. På Island betecknas den dock av hävd som en extremt ljus lokal gråsiska (Carduelis flammea 'islandica', ljus morf), men dessa ljusa isländska fåglar skiljer sig inte från snösiskor i andra trakter mer än i så måtto att de är intermediära i storlek mellan exilipes och hornemanni (Shirihai \& Svensson in prep.). Rasen hornemanni är stann- eller strykfågel och gör blott kortare vintertida förflyttningar, men den är rätt regelbundet anträffad i Skottland som tillfällig besökare under vinterhalvåret, och vissa år i större antal än annars.

Av underarten hornemanni finns ett svenskt fynd rapporterat i litteraturen, en ung hane insamlad av Sigvard Sjöberg den 27 april 1934 i Gällivare, Lule lappmark (Lundevall 1941). Exemplaret förvaras som skinn på Naturhistoriska Riksmuseet i Stockholm (NRM S 1). Det upptäcktes 1941 av Lundevall vid genomgång av Riksmuseets samling av grå- och snösiskor och sändes senare samma år till Finn Salomonsen i Köpenhamn för verifiering, vilket skedde efter jämförelse med Köpenhamnsmuseets samling.

Fågeln är stor och har lång vinge, $82 \mathrm{~mm}$, men ser annars ut som en gråsiska. Lundevalls beskrivning innehåller ingen närmare analys av hur gråoch snösiskor skulle skilja sig åt eller varför denna individ måste vara en hornemanni. Där står bara att 

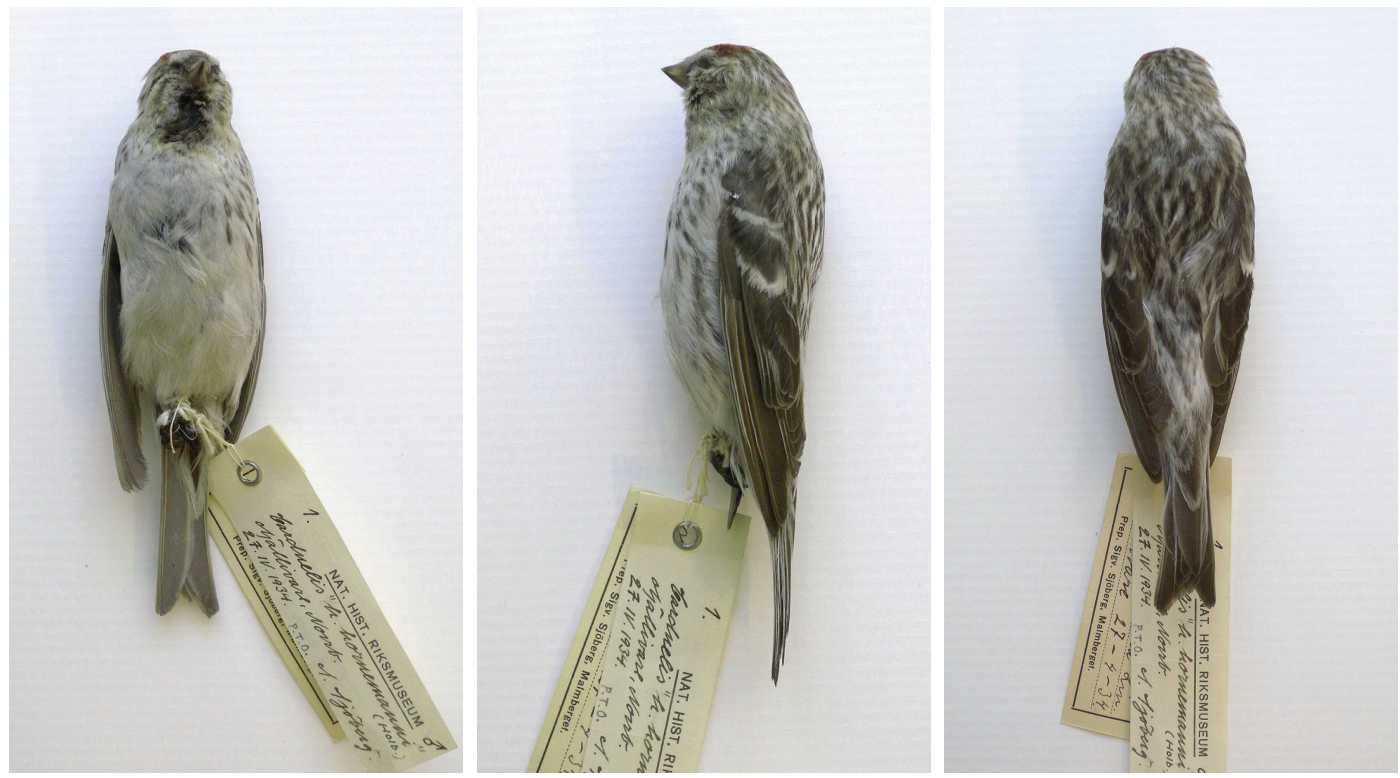

Figur 1. Exemplaret NRM S1, en gång föreslagen att vara en snösiska av rasen Carduelis hornemanni hornemanni, men som inte längre bör anses vara säkert art- eller rasbestämd.

The specimen NRM S1, once suggested to be an Arctic Redpoll of subspecies Carduelis hornemanni hornemanni but that should no longer be considered to be safely determined to species or subspecies.

den hade "en från de övriga i flera avseenden avvikande dräkt", men några preciseringar lämnas inte. Om övergumpen sägs något vilseledande att denna var "smutsvit, dock bakåt rent vit", men intet sägs om att hela övergumpen är kraftigt mörkfläckad. Man får utgå från att den avvikande långa vingen varit avgörande, och att Salomonsens utlåtande sedan fällt avgörandet.

Vid tiden för Lundevalls rapportering var veterligen inte vikten av teckningen hos de längsta undre stjärttäckarna känd. Snösiskans båda raser har endera helvita sådana täckfjädrar eller vita fjädrar med ett smalt och spetsigt mörkt skaftstreck, medan gråsiskan i 99\% av fallen har ett brett mörkt skaftstreck; blott enstaka gråsiskor har ett något smalare streck. Denna skillnad publicerades långt senare (Svensson 1970), och man måste ha förståelse för att Lundevall gjorde bästa möjliga bestämning utifrån den tidens kunskaper och litteratur. Gällivarefågeln i fråga har mycket breda och kraftiga centrala streck på undre stjärttäckarna och är alltså i det avseendet av gråsiskeutseende.

Jag har undersökt ett större antal skinn av samtliga taxa inom grå- och snösiskekomplexet. Gällivare-fågeln avviker från typiska hornemanni insamlade på Grönland eller i Quebec genom sin något mörkare helhet orsakad av kraftigare och mer omfattande streckning, genom sin helt fläckade låt vara ljusa övergump samt genom de kraftigt streckade längsta undre stjärttäckarna. Om man vill iaktta en sund försiktighet vid bedömning av förstafynd för landets fauna bör enligt min mening denna fågel inte bestämmas till en säker horneman$n i$. Den ser mest ut som en gråsiska men är för stor.

Vad rör det sig då om? Innan man kan svara på detta bör man komma ihåg, att variationen inom hela grå- och snösiskekomplexet är stor och möjligen $i$ vissa avseenden ännu outredd. Det finns en rik litteratur om detta. Frågan om huruvida gråsiskan och snösiskan hybridiserar är t.ex. omdebatterad. Ingen sådan samhäckning har konstaterats $i$ naturen, men att döma av rätt talrika mellanformer i museisamlingarna (kanske $2 \%$ av alla skinn), eller som fångas för ringmärkning, kan det inte uteslutas att viss hybridisering pågår. Den alternativa förklaringsmodellen är att den naturliga variationen hos yngre fåglar av båda arterna gör att ytterligheterna överlappar i karaktärer och skapar de svårbestämda individerna.

Framtida forskning får utvisa vilken av teorierna som är korrekt - kanske är det båda. Det räcker att konstatera att det irriterande ofta bland typiska fåglar dyker upp kniviga mellanformer, och att alla siskor inte går att säkert bestämma med nuvarande 
kunskaper.

Gällivare-fågeln är av allt att döma en sådan svårbestämd fågel. Med vinge $82 \mathrm{~mm}$ (Lundevall: $82)$, stjärt $63 \mathrm{~mm}(65,5)$, tars $16,0 \mathrm{~mm}(16)$, näbb till skallen $11,0 \mathrm{~mm}(10,0)$, näbb till fjäderfästet $8,3 \mathrm{~mm}(8,6)$ och näbbhöjd $7,1 \mathrm{~mm}(6,6)$ är den för stor för normala snösiskor av rasen exilipes och också för stor för normala gråsiskor av rasen flam$m e a$. Båda dessa har en vinglängd som inte överstiger $80 \mathrm{~mm}$, stjärtlängden är hos de två maximalt 62 respektive $61 \mathrm{~mm}$, och näbbhöjden är hos exilipes högst 7,0 mm.

Det finns en möjlighet att förklara fågeln som en varietet holboellii. Gråsiskor med denna beteckning är något mer storvuxna än normala gråsiskor, kan ha en vinglängd av $83 \mathrm{~mm}$ (35 sådana var. holboellii undersökta i Riksmuseets samling) och har framför allt en längre och litet kraftigare näbb. De är ofta också aningen kraftigare pigmenterade, även om detta är svårt att säkert fastställa eftersom de flesta insamlade är i sliten sommardräkt, som naturligt är något mörkare än vinter- och vårdräkter. En tolkning som var. holboellii skulle förklara Gällivare-fågelns storlek, men stämmer inte helt beträffande näbbens format.

Mitt förslag är att fågeln betraktas som en obestämbar aberrant gråsiska, möjligen med drag av var. holboellii. Den bör inte gälla som säkert bestämd hornemanni, vilken ras därmed fortfarande saknas på den svenska listan.

\section{Litteratur}

Lundevall, C.-F. 1941. Carduelis h. hornemanni (HolBøLL) funnen i Sverige. Fauna och Flora 36: 83-85.

Shirihai, H. \& Svensson, L. in prep. Handbook of Western Palearctic Birds. Helm, London.

Svensson, L. 1970. Identification Guide to European Passerines. 1:a uppl. Publ. av förf. Stockholm.

\section{Summary}

Two subspecies have been described of the Arctic Redpoll Carduelis hornemanni, the smaller exilipes in northern Eurasia and the larger horneman$n i$ in Greenland and North America. One record of the subspecies hornemanni has been published for Sweden (Lundevall 1941): a young male collected at Gällivare in Lapland on 27 April 1934 (specimen NRM S 1). The bird is large with a long wing, $82 \mathrm{~mm}$, but looks otherwise as a Common Redpoll Carduelis flammea (Figure 1). Both the upper and under tail-coverts are heavily streaked. At the time when Lundevall published the record it was not known that Arctic Redpolls of both subspecies have under tail-coverts that are purely white or white with only a very narrow and pointed shaft streak whereas almost all Common Redpolls have coverts with broad dark shaft streaks. I have examined a large number of specimen of all taxa within the redpoll complex. The focal bird simply looks like an unusually large Common Redpoll.

The measurements of the Gällivare bird are as follows (Lundevall's within parenthesis): wing 82 (82) $\mathrm{mm}$, tail $63(65.5) \mathrm{mm}$, tarsus 16.0 (16) $\mathrm{mm}$, bill to skull $11.0 \mathrm{~mm}(10.0)$, bill to feathering 8.3 (8.6) mm, bill depth 7.1 (6.6) mm. Normal Arctic Redpolls of subspecies exilipes and Common Redpolls of subspecies flammea are smaller with wing length not exceeding $80 \mathrm{~mm}$ and tail length not exceeding $62 \mathrm{~mm}$. Bill depth at feathering of exilipes is less than $7.0 \mathrm{~mm}$. The specimen could possibly be a variety of Carduelis flammea called holboellii. However, although the large size would indicate this, the bill shape is not perfect for var. holboellii, and the specimen is best regarded as an aberrant bird with no definite identification. The record of ssp. C. h. hornemanni should therefore in my opinion be removed from the Swedish list.

Lars Svensson, S:ta Toras väg 28, 26977 Torekov, Sverige.E-mail:lars@lullula.se

\section{Kortstjärtade liror Puffinus tenuirostris födosöker $i$ sedimentmolnen efter födosökande gråvalar Eschrichtius robustus}

\section{HENRIK KYLIN}

The terrestrial ecology research expedition "Beringia 2005" used the icebreaker Oden to transport researchers between field sites along the coast of Chukotka and Wrangel Island. In addition, some oceanographic work and chance bird observations 